\title{
Reverse rendezvous with endoscopic retrograde cholangiography and percutaneous transhepatic cholangio drainage: who meets whom?
}
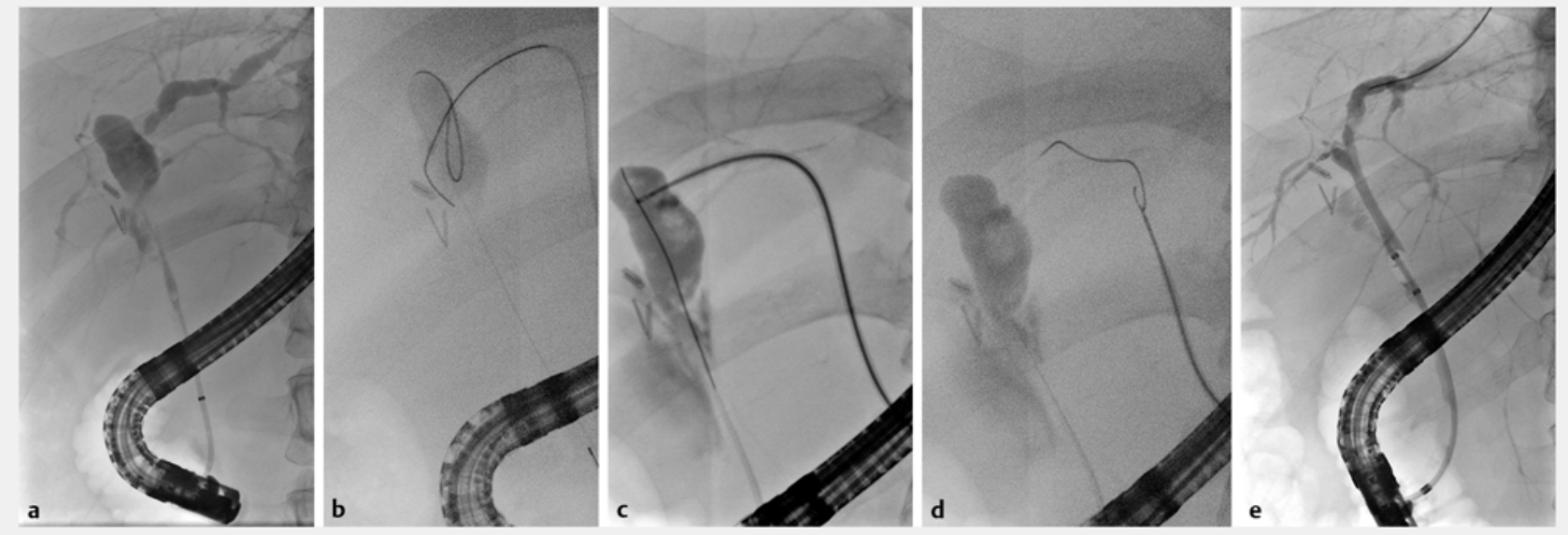

- Fig. 1 Cholangiographic images. a High grade common bile duct (CBD) stenoses, common hepatic duct (CHD) dilation to $15 \mathrm{~mm}$, and left hilar obstruction not amenable to endoscopic retrograde cholangiography-guided therapy. Right-sided loss of intrahepatic ducts was suspected previously. $\mathbf{b}$ Rendezvous of wires in the dilated CHD, but access across the significant stenoses was not possible. $\mathbf{c}, \mathbf{d}$ The transpapillary wire was grabbed with a forceps over an 8-Fr bougie and exteriorized percutaneously. e Resolution of stenoses in the CBD and CHD 14 months after initial rendezvous.

A 47-year-old severely ill Caucasian man presented with cholestasis (bilirubin $17.8 \mathrm{mg} / \mathrm{dL}$ ) due to primary sclerosing cholangitis. Endoscopic retrograde cholangiography (ERC) showed high grade strictures of the common bile duct (CBD), dilation of the common hepatic duct (CHD), and left hilar obstruction ( $\triangleright$ Fig.1a). Attempts to maneuver 5$7-\mathrm{Fr}$ bougies across the distal CBD stenosis were not successful.

Via left-sided percutaneous transhepatic cholangio drainage (PTCD), retrograde access to the CBD was not possible even after simultaneous transpapillary wire guidance ( $\mathbf{F i g} \mathbf{1} \mathbf{b}$ ). Therefore, a 1.2-mm biopsy forceps (SpyBite; Boston Scientific, Ratingen, Germany) was introduced percutaneously through an 8-Fr bougie into the dilated CHD to grab the transpapillary 0.025 -inch wire. The wire was carefully exteriorized in a reverse rendezvous maneuver ( $>$ Fig. 1 c, d, $>$ Video 1). Given the lack of bougienage options, a 5.2-Fr angiography catheter (Super Torque Plus; Cordis,

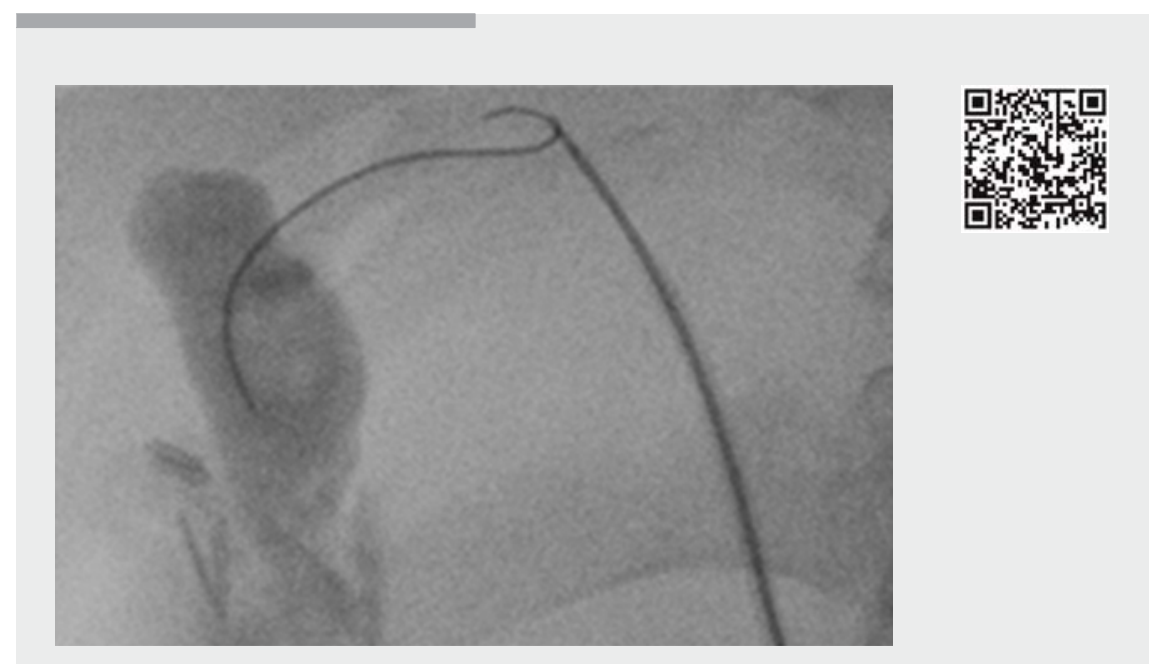

Video 1 Reverse rendezvous with endoscopic retrograde cholangiography and percutaneous transhepatic biliary drainage.

Baar, Switzerland) was inserted as a temporary spacer across the papilla under duodenoscopic view. Upon PTCD exchange, spurting bleeding from the access site was stopped by upgrade to an 8.5-Fr Yamakawa drain (Peter Pflugbeil GmbH, Zorneding, Germany). Parenchymal damage from initial wire manipulation was suspected, so the percutaneous tract was subsequently 
occluded with hemostyptic gelatine (Gelita; B. Braun, Melsungen, Germany), and a transpapillary $8.5-\mathrm{Fr}$ pigtail stent was inserted.

The patient gained $10 \mathrm{~kg}$ in weight and the bilirubin level persistently dropped to $0.8 \mathrm{mg} / \mathrm{dL}$. After repeated stent up-

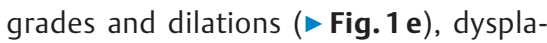
sia was ruled out by cholangioscopic biopsies. After 20 months, the patient was well and continued to have regular follow-up with no evidence of recurrence of cholestasis.

To our knowledge, reverse rendezvous, with percutaneous uptake of a transpapillary wire, has not been reported previously. The "lucky punch" of being able to grab the transpapillary wire with a port-guided forceps can be facilitated by $\mathrm{C}$-arm rotation. Unsheathed transparenchymal wire extraction is not recommended as the wire may cut the liver parenchyma, necessitating hemostyptic occlusion of the percutaneous tract, as in our patient. Reverse ERC-PTCD rendezvous is a nonstandard rescue maneuver that can offer significant benefit in technically demanding situations.
Endoscopy_UCTN_Code_CPL_1AK_2AH

\section{Competing interests}

Martin Goetz is in the advisory board for Boston Scientific.

The authors

Martin Goetz ${ }^{1}$, Jakob Fisch ${ }^{1}$, Jürgen Hetzel${ }^{2}$, Gerd Grözinger ${ }^{3}$

1 Innere Medizin I, Universitätsklinikum Tübingen, Tübingen, Germany

2 Innere Medizin II, Universitätsklinikum Tübingen, Tübingen, Germany

3 Radiologische Universitätsklinik, Universitätsklinikum Tübingen, Tübingen, Germany

Corresponding author

\section{Martin Goetz, MD}

Innere Medizin I, Universitätsklinikum Tübingen, 72076 Tübingen, Germany Fax: +49-7071-2925034

m_goetz@web.de
Bibliography

DOI https://doi.org/10.1055/a-0800-8342

Published online: 14.12.2018

Endoscopy 2019; 51: E47-E48

(c) Georg Thieme Verlag KG Stuttgart · New York

ISSN 0013-726X

\section{ENDOSCOPY E-VIDEOS}

https://eref.thieme.de/e-videos

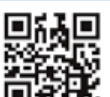

Endoscopy E-Videos is a free access online section, reporting on interesting cases and new

techniques in gastroenterological endoscopy. All papers include a high quality video and all contributions are freely accessible online.

This section has its own submission website at https://mc.manuscriptcentral.com/e-videos 